\title{
Health effects of ambient air pollution - recent research development and contemporary methodological challenges Cizao Ren ${ }^{* 1,2}$ and Shilu Tong ${ }^{1}$
}

\author{
Address: ${ }^{1}$ School of Public Health and Institute of Health and Biomedical Innovation, Queensland University of Technology, Kelvin Grove, QLD \\ 4059, Australia and ${ }^{2}$ Harvard School of Public Health, Exposure, Epidemiology and Risk Program, Landmark Center West, Suite 415, 401 Park Dr, \\ Boston, MA 02215, USA \\ Email: Cizao Ren* - rencizao@yahoo.com; Shilu Tong - s.tong@qut.edu.au \\ * Corresponding author
}

Published: 6 November 2008

Environmental Health 2008, 7:56 doi:10.1186/1476-069X-7-56

This article is available from: http://www.ehjournal.net/content/7/I/56

(c) 2008 Ren and Tong; licensee BioMed Central Ltd.

This is an Open Access article distributed under the terms of the Creative Commons Attribution License (http://creativecommons.org/licenses/by/2.0), which permits unrestricted use, distribution, and reproduction in any medium, provided the original work is properly cited.
Received: 29 January 2008

Accepted: 6 November 2008

\begin{abstract}
Exposure to high levels of air pollution can cause a variety of adverse health outcomes. Air quality in developed countries has been generally improved over the last three decades. However, many recent epidemiological studies have consistently shown positive associations between low-level exposure to air pollution and health outcomes. Thus, adverse health effects of air pollution, even at relatively low levels, remain a public concern. This paper aims to provide an overview of recent research development and contemporary methodological challenges in this field and to identify future research directions for air pollution epidemiological studies.
\end{abstract}

\section{Introduction}

It is well known that exposure to high levels of air pollution can adversely affect human health. A number of air pollution catastrophes occurred in industrial countries between 1950s and 1970s, such as the London smog of 1952 [1]. Air quality in western countries has significantly improved since the 1970s. However, adverse health effects of exposure to relatively low level of air pollution remain a public concern, motivated largely by a number of recent epidemiological studies that have shown the positive associations between air pollution and health outcomes using sophisticated time-series and other designs [2].

This review highlights the key findings from major epidemiological study designs (including time-series, casecrossover, panel, cohort, and birth outcome studies) in estimating the associations of exposure to ambient air pollution with health outcomes over the last two decades, and identifies future research opportunities. We do not intend for this to be a formal systematic literature review or meta-analysis, but to discuss issues we feel are vitally important based on the recent literature and our own experience. This paper is divided into two parts: firstly to summarize recent findings from major epidemiological studies, and secondly to discuss key methodological challenges in this field and to identify research opportunities for future air pollution epidemiological studies.

\section{Health effects of ambient air pollution Time-series studies}

There are a large number of time-series studies on the short-term health effects of air pollution, with the emphasis on mortality and hospital admissions by means of fitting Poisson regression models at a community level or ecological level. This type of time-series design is a major approach to estimating short-term health effects of air pollution in epidemiological studies for the last two decades. Many studies have found associations between daily changes in ambient particulate air pollution and increased cardiorespiratory hospital admissions [3-6], 
along with cardiorespiratory mortality [7-9] and all cause mortality [10]. Because numerous air pollution timeseries studies show that exposure to air pollution is associated with different kinds of human health outcomes, it is impossible to list results from all studies. Table 1 only selects major time-series studies on short-term health effects of particulate matter (PM) and ozone from different countries around the world published over the last two decades because these two air pollutants are important toxic agents and widely explored by the majority of air pollution epidemiological studies. Early findings have been systematically and thoroughly reviewed by other authors $[11,12]$.

Single-site time-series studies have been criticized because of exposure measurement errors, substantial variation of the air pollution effects and the heterogeneity of the statistical approaches used in different studies [13]. Recently, several multi-site time-series studies have been conducted in Europe and the United States. Two large collaborative air pollution projects in Europe and U.S. are summarised below.

In Europe, the APHEA (Air Pollution and Health: a European Approach) studies have provided many new insights. Initial studies were based on older data (APHEA1) [14] and a new series of studies (APHEA-2) used data of the $\mathrm{PM}_{10}$ fraction since the late 1990s [15]. The APHEA2 mortality studies covered over 43 million people and 29 European cities, which were all studied for more than 5 years in the 1990s. The combined effect estimate showed that all-cause daily mortality increased by $0.6 \%$ (95\% CI: $0.4 \%, 0.8 \%$ ) for each $10 \mu \mathrm{g} / \mathrm{m}^{3}$ increase in $\mathrm{PM}_{10}$ from data involving 21 cities. It was found that there was heterogeneity between cities with different levels of $\mathrm{NO}_{2}$. The estimated increase in daily mortality for an increase of $10 \mu \mathrm{g} /$ $\mathrm{m}^{3}$ in $\mathrm{PM}_{10}$ were $0.2 \%$ (95\% CI: $\left.0.0 \%, 0.4 \%\right)$, and $0.8 \%$ (95\% CI: $0.7 \%, 0.9 \%$ ) in cities with low and high average $\mathrm{NO}_{2}$, respectively [16]. The APHEA-2 hospital admission study involved 38 million people living in eight European cities. Hospital admissions for asthma and chronic obstructive pulmonary disease (COPD) increased by $1.0 \%$ (95\% CI: $0.4 \%, 1.5 \%$ ) per $10 \mu \mathrm{g} / \mathrm{m}^{3} \mathrm{PM}_{10}$ increment among people older than 65 years [15].

In the United States, the National Morbidity, Mortality and Air Pollution Studies (NMMAPS) focused on the 20 largest metropolitan areas in the USA, involving 50 million inhabitants, during 1987-94 [2]. All-cause mortality was increased by $0.5 \%$ (95\% CI: $0.1 \%, 0.9 \%)$ for each increase of $10 \mu \mathrm{g} / \mathrm{m}^{3}$ in $\mathrm{PM}_{10}$. The estimated increase in the relative rate of death from cardiovascular and respiratory disease was $0.7 \%$ (95\% CI: $0.2 \%, 1.2 \%$ ). Effects on hospital admissions were studied in ten cities with a combined population of 1843000 individuals older than 65 years [17]. The model used considered simultaneously the effects of $\mathrm{PM}_{10}$ up to the lag of 5 days and effects of $\mathrm{PM}_{10}$ on chronic obstructive pulmonary disease admissions to be $2.5 \%$ (95\% CI: $1.8 \%, 3.3 \%)$ and on cardiovascular disease admissions to be $1.3 \%$ (95\% CI: $1.0 \%, 1.5 \%$ ) for an increase of $10 \mu \mathrm{g} / \mathrm{m}^{3}$ in $\mathrm{PM}_{10}$. Bell et al. [18] analysed 95 NMMAPS community data to examine the association between ozone concentration and mortality, showing that a 10-ppb increase in the previous week's ozone was associated with a $0.5 \%$ (95\% posterior interval (PI), $0.3 \%$, $0.8 \%)$ increase in daily mortality and a $0.64 \%$ (95\% PI, $0.31 \%, 0.98 \%$ ) increase in cardiovascular and respiratory mortality. The effect estimates of the exposure over the previous week were larger than those considering only a single day's exposure. Recently, Dominici et al. [13] examined the short-term association between fine particulate air pollution and hospital admissions and found that exposure to $\mathrm{PM}_{2.5}$ was associated with different health outcomes. The largest association was observed for heart failure, and a $10 \mu \mathrm{g} / \mathrm{m}^{3}$ increase in $\mathrm{PM}_{2.5}$ was found to be associated with a $1.3 \%$ (95\% PI: $0.8 \%, 1.8 \%)$ increase in hospital admissions from heart failure on the same day.

Although time-series studies have shown that day-to-day variations in air pollutant concentrations are associated with daily deaths and hospital admissions, it is still unclear how many days, weeks or months of air pollution have brought such events forward. Harvesting or mortality/morbidity displacement means that some cases are occurring only in those to whom it would have happened in a few days anyway [19]. If so, the increase in cases immediately after exposure would be offset by a deficit in daily deaths a few days later $[19,20]$. If air pollution has harvesting effects, normal time-series models are unable to estimate the effects due to the issues of collinearity and statistical power. The polynomial distributed lag (PDL) model [21] and the time-scale model [19] have been adopted to explore whether air pollution has harvesting or displacement effects on daily deaths or hospital admissions. A few studies suggested potential harvesting effects of ambient air pollution while other studies have shown that there is no evidence for harvesting effects $[19,22,23]$. Although one study shows that potential bias might occur in PDL model [24], the estimated effects of ambient air pollutants seem to increase when longer lags of air pollution are included $[19,20]$.

\section{Case-crossover studies}

Case-crossover study design is an alternative approach to estimating short-term health effects of air pollution in epidemiological studies. In the last two decades, the casecrossover design has been applied in a large number of studies of air pollution and health [25-28]. For example, Neas et al. [27] used a case-crossover study design to estimate the association between air pollution and mortality 
Table I: Time-series studies of short-term health effects of air pollution after 2000

\begin{tabular}{|c|c|c|c|c|}
\hline Study & Pollutant & Population & Methodology & Main findings \\
\hline $\begin{array}{l}\text { Czech Republic and rural } \\
\text { region in Germany [83] }\end{array}$ & TSP & Mortality 1982-1994 & Poisson regression (GAM) & $\begin{array}{l}\text { Czech Republic: } 3.8 \% \text { increase } \\
(95 \% \text { Cl: } 0.8 \%, 9.6 \%) \text { per } 100 \\
\mu g / \mathrm{m}^{3} ; \text { No evidence for } \\
\text { association in the rural area in } \\
\text { German at the Czech border. }\end{array}$ \\
\hline 10 US cities [84] & $\mathrm{PM}_{10}$ & Mortality 1986-1993 & Poisson regression (GAM) & $\begin{array}{l}0.67 \% \text { increases for a } 10 \mu g / \\
\mathrm{m}^{3}(95 \% \mathrm{Cl}: 0.52 \%, 0.81 \%) \\
\text { No difference between } \\
\text { summer and winter. }\end{array}$ \\
\hline New Zealand [85] & $\mathrm{PM}_{10}$ & $\begin{array}{l}\text { Mortality Jun 1988-Dec } \\
1993\end{array}$ & Poisson regression (GAM) & $\begin{array}{l}\text { I\% increase for all-cause } \\
\text { mortality ( } 95 \% \mathrm{Cl}: 0.5 \% \text {, } \\
2.2 \%) ; 4 \% \text { increase for } \\
\text { respiratory diseases } \\
(95 \% \mathrm{Cl}: 1.5 \%, 5.9 \%)\end{array}$ \\
\hline 10 US cities [2I] & $\mathrm{PM}_{10}$ & Mortality 1986-1993 & $\begin{array}{l}\text { Distributed lag model } \\
\text { (GAM) }\end{array}$ & $\begin{array}{l}\text { I.4\% ( } 95 \% \mathrm{Cl}: 1.15 \%, \mathrm{I} .68 \%) \\
\text { increase for } 10 \mu \mathrm{gg} / \mathrm{m}^{3} \text { on a } \\
\text { single day using a quadratic } \\
\text { distributed lag model; I.3\% } \\
\text { increase }(95 \% \mathrm{Cl}: 1.04 \% \text {, } \\
\text { I.56\%) using an unstrained lag } \\
\text { model }\end{array}$ \\
\hline
\end{tabular}

20 US cities [2] $\quad \mathrm{PM}_{10}, \mathrm{O}_{3}, \mathrm{SO}_{2}, \mathrm{CO}, \mathrm{NO}_{2}$ Mortality I987-1994

$\mathrm{PM}_{10}: 0.51 \%$ increase $(95 \% \mathrm{Cl}$ : $0.07 \%, 0.93 \%)$ per $10 \mu g / \mathrm{m}^{3}$ for all causes; $0.68 \%$ increase per $10 \mu g / \mathrm{m}^{3}$ for cardiovascular and respiratory diseases

(95\% Cl: $0.20 \%, 1.16 \%)$

$\mathrm{O}_{3}$ : weaker evidence during the summer;

Other pollutants: no evidence

Hong Kong [86] $\quad \mathrm{PM}_{10}, \mathrm{SO} 2 \quad$ Morality 1995-1998

Significant associations were found between mortalities for all respiratory diseases and ischaemic heart diseases (IDH). The increases for all respiratory mortalities (for a $10 \mu \mathrm{g} / \mathrm{m}^{3}$ increase in the concentration) are $0.8 \%(95 \%$ Cl: $0.1 \%, 1.4 \%$ ) for $\mathrm{PM}_{10}$ and I.5\% (95\% Cl: $0.1 \%, 2.9 \%)$ for $\mathrm{SO}_{2}$; the increases for IDH are $0.9 \%(95 \% \mathrm{Cl}: 0.0 \%, 1.8 \%)$ for $\mathrm{O}_{3}$ and $2.8 \%(95 \% \mathrm{Cl}$ : $1.2 \%, 4.4 \%$ ) for $\mathrm{SO}_{2}$.

\begin{tabular}{|c|c|c|c|c|}
\hline Seoul Korea[87] & $\mathrm{PM}_{10}$ & Mortality 1995-1999 & Poisson regression (GAM) & $\begin{array}{l}3.7 \% \text { increase }(95 \% \mathrm{Cl}: 2.1 \% \text {, } \\
5.4 \%) \text { for non-accident causes, } \\
13.9 \% \text { increase }(95 \% \mathrm{Cl}: 6.8 \% \text {, } \\
21.5 \%) \text { for respiratory } \\
\text { disease, } 4.4 \% \text { increase }(95 \% \\
\mathrm{Cl}:-1.0 \%, 9.0 \%) \text { for } \\
\text { cardiovascular disease and } \\
6.3 \% \text { increase }(95 \% \mathrm{Cl}: 2.3 \% \text {, } \\
10.5 \%) \text { for cerebrovascular } \\
\text { disease per } \mathrm{IQR} \text { increase of }_{\mathrm{PM}_{10}\left(43.12 \mu \mathrm{gg} / \mathrm{m}^{3}\right)}\end{array}$ \\
\hline
\end{tabular}


Table I: Time-series studies of short-term health effects of air pollution after 2000 (Continued)

\begin{tabular}{|c|c|c|c|c|}
\hline Shanghai, China [88] & $\mathrm{PM}_{10}, \mathrm{SO}_{2}, \mathrm{NO}_{2}$ & $\begin{array}{l}\text { Mortality Jun } 2000 \text { to Dec } \\
2001\end{array}$ & Poisson regression (GAM) & $\begin{array}{l}0.3 \% \text { increase }(95 \% \mathrm{Cl}: 0.1 \% \text {, } \\
0.5 \%) \text { for } \mathrm{PM}_{10}, 1.4 \% \text { increase } \\
(95 \% \mathrm{Cl}: 0.8 \%, 2.0 \%) \text { for } \mathrm{SO}_{2} \\
\text { and } 1.5 \% \text { increase }(95 \% \mathrm{Cl} \\
0.8 \%, 2.2 \%) \text { for } \mathrm{NO}_{2} \text { per } 10 \\
\mu \mathrm{g} / \mathrm{m}^{3}\end{array}$ \\
\hline
\end{tabular}

\begin{tabular}{lll}
\hline Brisbane, Australia [89] $\mathrm{BSP}, \mathrm{O}_{3}, \mathrm{SO}_{2}, \mathrm{NO}_{2}$ & $\begin{array}{l}\text { Hospital admission 1987- } \\
1994\end{array} \quad$ Poisson regression (GLM)
\end{tabular}

\section{BSP: $1.5 \%$ increase $(95 \% \mathrm{Cl}$ : $0.6 \%, 2.3 \%)$ for respiratory diseases per $24-\mathrm{hr} 10^{-5} / \mathrm{m}$ increase. $\mathrm{O}_{3}: 2.3 \%$ increase $(95 \% \mathrm{Cl}$ : $0.6 \%, 2.3 \%$ ) for respiratory disease per 8-hr unit increase. $\mathrm{SO}_{2}: 8.0 \%$ increase $(95 \% \mathrm{Cl}$ : $3.0 \%, 13.1 \%$ ) for respiratory disease per 24-hr unit increase. \\ $\mathrm{NO}_{2}:-0.1 \%$ increase $(95 \% \mathrm{Cl}$ : $-0.3 \%, 0.2 \%$ ) for respiratory disease per I-hr-max unit increase.}

\begin{tabular}{lll}
\hline Brazil [90] & $\mathrm{PM}_{10}, \mathrm{O}_{3}, \mathrm{SO}_{2}, \mathrm{CO}, \mathrm{NO}_{2}$ & $\begin{array}{l}\text { Respiratory disease } \\
\text { Hospital admission 1993- } \\
1997\end{array}$
\end{tabular}

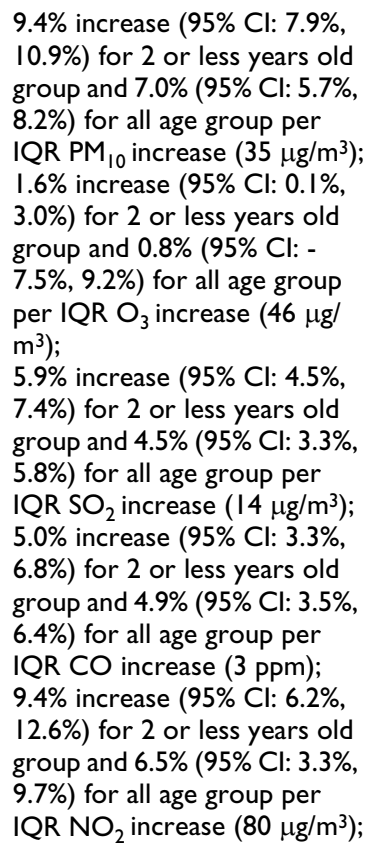
group and $7.0 \%$ ( $95 \% \mathrm{Cl}: 5.7 \%$, $8.2 \%$ ) for all age group per IQR PM 10 increase $\left(35 \mu \mathrm{g} / \mathrm{m}^{3}\right)$; I.6\% increase $(95 \% \mathrm{Cl}: 0.1 \%$, $3.0 \%$ ) for 2 or less years old group and $0.8 \%(95 \% \mathrm{Cl}$ : $7.5 \%, 9.2 \%$ ) for all age group per IQR $\mathrm{O}_{3}$ increase $(46 \mu \mathrm{g})$ $\mathrm{m}^{3}$ );

$5.9 \%$ increase ( $95 \% \mathrm{Cl}: 4.5 \%$, $7.4 \%$ ) for 2 or less years old group and $4.5 \%$ ( $95 \% \mathrm{Cl}: 3.3 \%$, $5.8 \%$ ) for all age group per IQR SO 2 increase $\left(14 \mu \mathrm{g} / \mathrm{m}^{3}\right)$; $5.0 \%$ increase $(95 \% \mathrm{Cl}: 3.3 \%$, $6.8 \%)$ for 2 or less years old group and $4.9 \%$ ( $95 \% \mathrm{Cl}$ : 3.5\%, $6.4 \%$ ) for all age group per IQR CO increase (3 ppm); $9.4 \%$ increase $(95 \% \mathrm{Cl}: 6.2 \%$, $12.6 \%$ ) for 2 or less years old group and $6.5 \%$ (95\% Cl: $3.3 \%$, 9.7\%) for all age group per IQR NO${ }_{2}$ increase $\left(80 \mu \mathrm{g} / \mathrm{m}^{3}\right)$;

in Philadelphia and found a $100 \mu \mathrm{g} / \mathrm{m}^{3}$ increment in the 48 hours mean level of TSP was associated with increased all-cause mortality (odds ratio $(\mathrm{OR})=1.06$; 95\% CI: 1.03 , 1.09). A similar association was observed for deaths in individuals over 65 years of age (OR: 1.07; 95\% CI: 1.04, 1.11). Levy et al. [28] estimated the effect of short-term changes in exposure to particulate matter on the rate of sudden cardiac arrest. The cases were obtained from a previously conducted population-based case-control study and were combined with ambient air monitoring data. The results did not show any evidence of a short-term effect of particulate air pollution on the risk of sudden cardiac arrest in people without previously recognised heart disease. Schwartz [26] conducted a case-crossover study to examine the sensitivity of the association between ozone and mortality when adjusted for temperature and found that 10-ppb increase of maximum hourly ozone was associated with $0.23 \%$ (95\% CI: $0.01 \% \sim 0.44 \%$ ) increase in daily deaths after adjusting for temperature in 14 US cities. Barnett et al. [25] examined the association between air pollution and cardio-respiratory hospital admissions in Australia and New Zealand cities. The results show that air pollution arising from common emission sources was significantly associated with cardiovascular health outcomes in the elderly. For example, for a 0.9-ppm increase in $\mathrm{CO}$, there were significant increases in elderly hospital 
admissions for 2.2\% (95\% CI: $0.9 \%, 3.4 \%$ ) increase of total cardiovascular disease and $2.8 \%$ (95\% CI: $1.3 \%$, $4.4 \%$ ) increase of all cardiac disease.

\section{Panel studies}

Many air pollution panel studies have been conducted, including several large longitudinal studies of air pollution and health effects such as the Southern California Children's Health Study [29,30], in which children from grades 4,7 , and 10 residing in twelve communities near Los Angeles were followed annually. The results indicated that exposure to ambient particles, $\mathrm{NO}_{2}$, and inorganic acid vapour was associated with reduced lung function in children. Another large panel study, the Pollution Effects on Asthmatic Children in Europe (PEACE), was designed to examine the relationship between short-term changes in air pollution and lung function, respiratory symptoms and medication use [31]. This project was conducted in 14 centres using a common protocol in the winter of 19931994. Each PEACE centre involved an urban and a rural panel of symptomatic children and followed at least seventy-five 6-12 year old children [31]. The pooled estimates of two literature reviews which were separately conducted about the PEACE study and showed that no clear relation could be established for changes in $\mathrm{PM}_{10}$ black smoke, $\mathrm{SO}_{2}$ and $\mathrm{NO}_{2}$ and changes in respiratory health. The non-significant effects were thought to be possibly due to the short observation period. Ward and Ayres [32] reviewed 22 panel studies published in the 1990 s to estimate the overall effects of ambient particles on children. Results show that the majority of identified panel studies indicated an adverse effect of particulate air pollution. Several recent panel studies also show that particulate air pollution is associated with human health [33-37].

\section{Cohort studies}

Compared to time-series and case-crossover studies, there are only a few large cohort studies. About a dozen cohort studies have been conducted in the United States [38-44], Europe [45-48] and Australia [49]. A cohort study conducted by Dockery et al. [39] in six U.S. cities shows that there was a statistically significant and robust association between air pollution and mortality. The adjusted mortality rate ratio for the most polluted city was 1.26 (95\% CI: 1.08-1.47) compared with the least polluted city. Air pollution was also associated with deaths from lung cancer and cardiopulmonary diseases. Abbey et al. [38] conducted a cohort study during 1973-1992 to estimate effect of exposure to long-term ambient concentrations of $\mathrm{PM}_{10}$ and other air pollutants, and show that $\mathrm{PM}_{10}$ was strongly associated with mortality from respiratory disease for both sexes adjusting for a wide range of potentially confounding factors. The relative risk (RR) for an interquartile range (IQR) difference of $\mathrm{PM}_{10}$ was 1.18 (95\% CI: 1.42, 3.97). Ozone was strongly associated with lung cancer mortality for males for the IQR difference (RR: 4.19; 95\% CI: 1.81, 9.69). Sulphur dioxide was also strongly associated with lung cancer mortality for both sexes. Pope et al. [44] conducted one cohort study in the US to examine the long-term effect of exposure to fine particulate air pollution. They found that fine particulate and sulphur oxide-related pollution were associated with allcause, lung cancer and cardiopulmonary mortality. A 10 $\mu \mathrm{g} / \mathrm{m}^{3}$ increase in fine particulate air pollution was associated with an increase of $4 \%, 6 \%$, and $8 \%$ for all-cause, cardiopulmonary, and lung cancer mortality, respectively. Hoek et al. [48] investigated a random sample of 5000 people and 489 of 4492 (11\%) died during 1986-1994 in the Netherlands fining that cardiopulmonary mortality was associated with living near a major road with relative risk of 1.95 (95\% CI: 1.09-3.52). A cohort study conducted by Filleul et al. [46] in France found that urban air pollution to be associated with increased mortality over 25 years in France. Frostad et al. [47], in a 30-year followup cohort study in Norway, found that respiratory symptoms were a significant predictor of mortality from all causes. In Australia, Jalaludin et al.[49] enrolled a cohort of primary school children with a history of wheeze $(\mathrm{n}=$ 148 ) in an 11-month longitudinal study to examine the association between ambient air pollution and respiratory morbidity. They found that $\mathrm{PM}_{10}$ and $\mathrm{NO}_{2}$, but not ozone, were significantly associated with doctor visits for asthma.

\section{Birth outcome studies}

Even though effects of exposure to ambient air pollution on mortality and hospital admissions have been increasingly demonstrated over the past 30 years, exploring its adverse impact on pregnant outcomes has only begun since the last decade [50]. Because pregnancy is a period of human development particularly susceptible to the influence of many environmental factors due to high cell proliferation, organ develop and the changes of capabilities of fetal metabolism, the relative short-term period provides a unique opportunity to study the adverse effects of ambient toxins on human health [51]. The majority of birth outcome studies are based on large datasets routinely collected from air pollution monitoring systems and birth registration processes, and therefore, in general, the statistical power is strong [52-59]. Logistic regression models or linear regression models at the individual level are usually adopted to assess the effects of ambient air pollution on adverse birth outcomes adjusting for potential confounders including maternal age, maternal race, parity, fetal gender, season, gestational period, etc. Birth outcomes usually include low birth weight, preterm delivery and other biomarkers such as birth defect and ultrasound measures of head circumference. Personal exposures are often estimated at different terms, including the full gestation, trimesters, month after the pregnancy or before the time of delivery, etc. 
Many studies have shown that there are significant associations between exposure to ambient air pollutants and adverse birth outcomes [52-60]. For example, Liu et al. [53] found that 5-ppb increase of sulfur dioxide was associated with an 11\% (95\% CI: 1\%, 22\%) increase of low birth weight $(<2500$ grams) during the first month gestation and with a $9 \%$ increase of preterm delivery in Vancouver, Canada. A 1.0 ppm increase of carbon monoxide during the last month of pregnancy was associated with an $8 \%$ increase of preterm delivery. Parker et al. [60] selected population within 5 miles of over 40 air pollution monitoring sites across 28 California counties to estimate the adverse effects of air pollution and found that per $10 \mu \mathrm{g} / \mathrm{m}^{3}$ PM increase was associated with $13 \mathrm{~g}$ (95\% CI: 7.6 g, $18.3 \mathrm{~g}$ ) decrease of birth weight. Similarly, Ritz et al. [59] conducted a population-nested case-control study to examine associations between air pollution and birth outcomes in Los Angeles and found that air pollution exposure was associated with preterm birth. Hansen et al. [58] examined the associations of exposure to ambient air pollution during early pregnancy with fetal ultrasonic measurements during mid-pregnancy in Australia. They found that a reduction in fetal abdominal circumference was associated with exposure to $\mathrm{O}_{3}$ during the days 31-60 of pregnancy $(-1.42 \mathrm{~mm}, 95 \% \mathrm{CI}:-2.74,-0.09)$, SO2 during the days 61-90 (-1.67 mm, 95\% CI: -2.94, $0.40)$, and $\mathrm{PM}_{10}$ during the days $90-120$ (-0.78 $\mathrm{mm}, 95 \%$ CI: $-1.49,-0.08)$.

\section{Implications of weak health effects}

Even though the association of air pollution with health outcomes is weak, it still has strong public health implications. One reason is that air pollution is ubiquitous and affects the whole population in most metropolitan cities. Another reason is that residents are continuously and permanently exposed to air pollution, which may have both short- and long-term effects on health outcomes. Some intervention studies have shown that the reduction in air pollution has resulted in an improvement in population health [55,61]. For example, Hedley et al. [61] reported that cardiovascular, respiratory and all cause mortality reduced by $2.0 \%$ (p<0.05), 3.9\% (p<0.05) and 2.1\% (p $<0.05)$ respectively in the first 12 months after an introduction of the restrictions on sulphur content of fuel in Hong Kong.

\section{Contemporary methodological challenges}

Air pollution epidemiologic research is challenged by the complexity of human exposure to environmental agents and by the difficulty of accurately measuring exposure. Residents are usually ubiquitously exposed to air pollution. In order to detect small effects of air pollution, both high statistical power and sophisticated study design are required. In addition, the characteristics of air pollutants vary and their concentrations change both spatially and temporally. Although everyone is susceptible to high concentration of pollution, its concentrations are not evenly distributed across populations. Due to such complexities, there are still many research questions to be addressed by future air pollution epidemiological studies. The following section discusses these issues.

\section{Shape of exposure response curve}

The shape of the exposure and response curve is very important. A key research question to be addressed is whether a threshold exists below which a certain air pollutant has no effect on population health. If such a threshold could be identified, public health benefits would be expected from bringing the pollutant below this level. Both theoretical and empirical works have been done to shed light on this issue $[62,63]$. In the analysis of NMMAPS data, no threshold evidence was found for the relationship between $\mathrm{PM}_{10}$ and daily all-cause and cardiorespiratory mortality [63]. By contrast, a threshold of about $50 \mu \mathrm{g} / \mathrm{m}^{3}$ was indicated for non-cardiorespiratory causes of death - viz, below this point, $\mathrm{PM}_{10}$ had little influence on non-cardiorespiratory mortality. These issues remain to be clarified.

\section{Model uncertainty and bias}

The process of model selection includes how to select covariates (eg, meteorological variables and co-pollutants), lag structure for air pollutants and the number of degrees of freedom for smoothing functions to adjust for longterm trend, short fluctuation, seasonality, other covariates and the determination of referent in case-crossover design. Studies have shown that the model choice will impact on estimates of relative risk [64]. As a result, many authors attempted to estimate the effects using the best single lag or combination of lags for meteorological factors and/or air pollutants and to identify the best degree of freedom for smoothing to adjust for different potential confounders. Some types of data can use several different models. Some authors do not clearly state why they select models and how they conduct data analyses. For example, when we estimate associations between exposure to air pollution and recurrent asthma episodes, based on different assumptions, at least five survival Cox models could be applied to estimate the associations between exposure to air pollution and asthma episodes [65]. Different assumptions or models may result in different estimates, and sometimes the difference is considerable. The choice of software options may cause this kind of uncertainty as well [65].

Results presented by the "best" final models are likely to cause publication bias because stronger and positive estimates tend to be published but negative results are usually difficult to be published. Multi-site time series design in which all data are analysed using the same model is one 
way to solve this problem. However, model uncertainty still exists in a multi-site study to some extent due to the model choice. Some studies have used Bayesian Model Averaging (BMA) to take into account uncertainties in model choice when making an inference [64]. BMA uses hierarchical models. The predictions and inferences are based on multiple models rather than a single model. Predictions are obtained by forming weighted averages of predictions over the different models where weights depend on the degree to which the data support each model.

Measurement errors of exposure to air pollution and potential confounders usually exist in air pollution epidemiological studies and it is impossible to be solved in most air pollution studies [66]. Due to spatial and temporal variations, data obtained in air pollution central monitors are not well representative of individual exposures. Some models are used to assess individual exposure to air pollution $[66,67]$, but they could not efficiently adjust for measurement errors. Therefore, potential misclassification bias of exposure is one of the main concerns in air pollution studies.

There are both spatial and temporal variations for exposure and outcomes in air pollution studies [68]. Both times-series and case-crossover designs at a community level can efficiently adjust for some measured and unmeasured time-invariant characteristics of the subjects (such as gender, age, smoking status and spatial characteristics) via matching, and therefore, the potential confounding from these measured and unmeasured characteristics is minimised $[69,70]$. The key concern for these designs is how to control for temporal confounding and meteorological variables, such as seasonality, shortterm variations and weather conditions (eg, temperature and humidity). In a prospective cohort study design, a major issue is how to identify a cohort with a sufficient variation in cumulative exposures, particularly when data recorded in central monitoring stations are used to measure ambient air pollution levels [44]. However, in maximizing the geographical variability of exposure the relative risk estimates from cohort studies are likely to be confounded by area-specific characteristics [68]. Due to collection of relatively detailed individual characters and sufficient adjustment for potential individual social and economic status, such confounding might be efficiently adjusted for.

Birth outcome studies are mainly based on routinely collected data, including exposure, outcome and potential confounders [52-60]. Most studies use pollution data obtained from the different monitors and the closest residential monitoring data are used as exposure proxies $[58,60,71,72]$. In general, information related to birth outcomes is well recorded in birth registration systems. However, the data may not include complete and accurate information on other potential confounders, such as maternal social and economic status and life styles. Birth outcome data analyses are usually conducted at an individual level. Therefore, this design is inherently vulnerable to some potential biases, including both temporal and spatial misclassification bias. Ritz and Wilhelm [73] has discussed the methodological issues of birth outcome designs in detail, and this review would not repeat these issues but rather than focus on potential bias in relation to spatial variation, which was ignored in their review, in the following section.

In birth outcome studies, both exposure and outcome data include temporal and spatial variations to some extent. The majority of birth outcome studies have adjusted for temporal and other confounders which are related to delivery information, including season, maternal age and race, fetal gender, parity, and maternal education attainment $[52-60,71,72]$. However, so far, few studies have paid much attention to the potential spatial confounding. Unlike time-series or case-crossover studies, most birth outcome studies lack the ability for automatic adjustment for measured and unmeasured time-invariant spatial variations. Unlike cohort studies, birth outcome study designs also lack the ability to efficiently adjust for personal life styles and social and economic status due to the lack of the detailed information available in routinely collected data. Because both exposure to air pollution and birth outcomes are influenced by some geographic characteristics, such as land use, forest, public infrastructure, and residential social and economic status, etc, the previous birth outcome studies might introduce bias to some extent due to the failure to consider spatial variation. In general, these spatial-related factors are favourable to links between air pollution exposure and birth outcomes. Therefore, we presume that the stronger associations reported in the previous birth outcome studies might partially attribute to this kind of bias. The simple way to adjust for the spatial variation is to add a categorical variable for individual residential areas to fit a fixed effect model or to include the residential areas to fit a mixed model or a random effect model.

\section{Interaction of temperature and air pollution}

In many locations, patterns of air pollution are driven by weather. Therefore, concentrations of air pollutants may be associated with temperature. Therefore, it may be possible that temperature and air pollution interact to affect health outcomes. Although effect modification has important public health implications [74], this issue has so far received limited attention, probably because of methodological complexity and the difficulty in data interpretation. Several studies examined whether or not 
ambient air pollution and temperature interact to affect human health outcomes, but they produced conflicting results [75-78]). For example, Samet et al. [78] investigated the sensitivity of the particulate air pollution mortality effect estimate to alternative methods of controlling weather and did not find any evidence that weather conditions modified the associations of particulate air pollution and sulphur dioxide with mortality, regardless of approaches of synoptic weather conditions. Katsouyanni et al. [75] used a multiple linear regression to investigate the interaction between air pollution and high temperature during a heat wave in Athens in July 1987. They found that while the main effects of air pollution index were not statistically significant, there was statistically significant synergistic effect between high levels of sulphur dioxide and high temperature $(\mathrm{P}<0.05)$. Roberts [77] found evidence that the effect of particulate air pollution on mortality might depend on temperature but the synergistic effect was sensitive to the number of degrees of freedom used in confounder adjustments. Recently, we found that temperature and particulate matter symmetrically enhanced the effect [76]. Since then, several multiple-site studies have found evidence that temperature and air pollutants interacted to impact human health but the nature and magnitude of such an interaction varied with geographic area [79-82]. Thus, further research is needed to examine the interactive effects between air pollutants and temperature on mortality and morbidity, especially in different spatial settings.

\section{Conclusion}

Many time-series, case-crossover and panel studies have shown that there are consistent short-term effects of air pollution on health outcomes (hospital admissions or deaths). Some cohort studies have also shown long-term health effects of air pollution. In spite of the weak associations of air pollution with human morbidity or mortality, its public health implications are strong because exposure to air pollution is ubiquitous and widespread. However, there are several key methodological challenges in the estimation of the health effects of low-level exposure to air pollution, such as the shape of the exposure response curve, threshold of air pollution, interactive effects of air pollution and weather conditions, and model uncertainty and potential bias. Future research efforts should focus on these important issues.

\section{Competing interests}

The authors declare that they have no competing interests.

\section{Authors' contributions}

CR conceived of the study, participated in its design, and is responsible for the draft of the manuscript. ST participated in the study design and revised the draft of the manuscript.

\section{Acknowledgements}

We thank Prof. Gail Williams, School of Population Health, University of Queensland for the comments on the earlier version of the manuscript. We also thank two reviewers for their insightful and constructive comments.

\section{References}

I. Ministry of Health: Mortality and morbidity during the London fog of December 1952. Reports on Public Health and Medical Subjects. Issue 95 London: HMSO; 1954.

2. Samet J, Dominici J, Curriero F, Coursac I, Zeger SL: Fine particulate air pollution and mortality in 20 US cities, I 987-I 994. N Engl J Med 2000, 343: I 742-1749.

3. Anderson H, Ponce de Leon A, Bland J, Bower JS, Strachan DP: Air pollution and daily mortality in London: 1987-92. BMJ I996, 3 I 2:665-669.

4. Burnett B, Brook J, Yung W, Dales RE, Krewski D: Association between ozone and hospitalization for respiratory diseases in 16 Canadian cities. Environ Res 1997, 72:24-31.

5. Linn W, Szlachcic Y, Gong H, Kinney PL, Berhane KT: Air pollution and daily hospital admissions in metropolitan Los Angeles. Environ Health Perspect 2000, 108:427-434.

6. Moolgavkar SH, Luebeck EG, Anderson EL: Air pollution and hospital admissions for respiratory causes in Minneapolis-St. Paul and Birmingham. Epidemiology I997, 8:364-370.

7. Hoek G, Brunekreef B, Fischer P, Wijnen JV: The association between air pollution and heart failure, arrhythmia, embolism, thrombosis, and other cardiovascular causes of death in a time series study. Epidemiology 200I, I 2:355-357.

8. Mar T, Norris G, Koenig J, Larson TV: Associations between air pollution and mortality in Phoenix, 1995-1997. Environ Health Perspect 2000, I 08:347-353.

9. Rossi G, Vigotti MA, Zanobetti A: Air pollution and cause specific mortality in Milan, Italy, 1980-1989. Arch Environ Health 1999, 54:I58-I64.

10. Roemer W, van Wijnen J: Daily mortality and air pollution along busy streets in Amsterdam, 1987-1998. Epidemiology 2001, I 2:649-653.

II. Brunekreef B, Holgate ST: Air pollution and health. Lancet 2002, 360: $1233-1242$.

12. Nyberg F, Pershagen G: Epidemiological studies on the health effects of ambient particulate air pollution. Scan J Work Environ Health 2000, 26(suppl I):49-89.

13. Dominici F, Peng R, Bell M, Pham L, McDermott A, Zeger SL, Samet JM: Fine particulate air pollution and hospital admission for cardiovascular and respiratory diseases. JAMA 2006, 295: I I27-II34.

14. Katsouyanni K, Touloumi G, Spix C, Schwartz J, Balducci F, Medina S, Rossi G, Wojtyniak B, Sunyer J, Bacharova L, Schouten JP, Ponka A, Anderson HR: Short-term effects of ambient sulphur dioxide and particulate matter on mortality in 12 European cities: results from time series data from the APHEA project. BMJ |997, 3 | 4: 1658-1663.

15. Atkinson R, Anderson H, Sunyer J, Ayres J, Baccini M, Vonk J, Boumghar A, Forastiere F, Forsbert B, Touloumi G, Schwartz J, Katsouyanni $\mathrm{K}$ : Acute effects of particulate air pollution on respiratory admissions: results from APHEA 2 project. Am J Respir Crit Care Med 200I, I 64:1860-1866.

16. Katsouyanni K, Touloumi G, Samol E, Gryparis A, Tertre AL, Monopolis Y, Rossi G, Zmirou D, Ballester F, Boumghar A, Anderson HR, Wojtyniak B, Paldy A, Braunstein R, Pekkanen J, Schindler C, Schwartzet J: Confounding and effect modification in the short-term effects of ambient particles on total mortality: results from 29 European cities within the APHEA-2 project. Epidemiology 2001, I 2:521-531.

17. Zanobetti A, Schwartz J, Dockery D: Airborne particles are a risk factor for hospital admissions for heart and lung disease. Environ Health Perspect 2000, I 08: I07I-1077.

18. Bell M, McDermott A, Zeger S, Samet JM, Dominici F: Ozone and short-term mortality in 95 US urban communities, I9872000. JAMA 2004, 292:2372-2378.

19. Zanobetti A, Schwartz J, Samoli E, Gryparis A, Touloumi G, Atkinson R, Tertre AL, Bobros J, Celko M, Goren A, Forsberg B, Michelozzi P, Rabczenko D, Ruiz EA, Katsouyanni K: The temporal pattern of mortality responses to air pollution: a multicity assessment of mortality displacement. Epidemiology 2002, 13:87-89. 
20. Schwartz J: Is there harvesting in the association of airborne particles with daily deaths and hospital admission? Epidemiology 200I, I 2:55-6I.

21. Schwartz J: The distributed lag between air pollution and daily deaths. Epidemiology 2000, I I:320-326.

22. Zanobetti A, Schwartz J, Samoli E, Gryparis A, Touloumi G, Peacock J, Anderson RH, Lertre AL, Bobros J, Celko M, Goren A, Forsberg B, Michelozzi P, Rabczenko D, Hoyos SP, Wichmann HE, Katsouyanni K: The temporal pattern of respiratory and heart disease mortality in response to air pollution. Environ Health Perspect 2003 I I I(9): I I88-I I 93.

23. Goodman PG, Dockery DW, Clancy L: Cause-specific mortality and the extended effects of particulate pollution and temperature exposure. Environ Health Perspect 2004, I I 2: I79- 185.

24. Roberts S, Switzer P: Mortality Displacement and Distributed Lag Models. Inhal Toxicol 2004, I 6:879-888.

25. Barnett A, Williams G, Schwartz J, Best TL, Neller AH, Petroeschevsky AL, Simpson RW: The effects of air pollution on hospitalizations for cardiovascular disease in elderly people in Australia and New Zealand cities. Environ Health Perspect 2006, I | 4:1018-1023.

26. Schwartz J: How sensitive is the association between ozone and daily deaths to control for temperature? Am J Respir Crit Care Med 2005, I 7 I:627-631.

27. Neas L, Schwartz J, Dockery D: A case-crossover analysis of air pollution and mortality in Philadelphia. Environ Health Perspect | 999, | 07:629-63|.

28. Levy D, Sheppard L, Checkoway H, Kaufman J, Lumley T, Koenig J, Siscovick D: A case-crossover analysis of particulate amtter air pollution and out-of-hospital primary cardiac arrest. Epidemiology 200I, I 2:193-199.

29. Guaderman W, McConnell R, Gilliland F, London S, Thomas D, Avol E, Vora H, Berhane K, Rappaport EB, Lurmann F, Margolis HG, Peters J: Association between air pollution and lung function growth in southern California children. Am J Respir Crit Care Med 2000, 162:1383-1390.

30. Peters J, Avol E, Gaundman W, Linn WS, Navidi W, London SJ, Margolis H, Rappaport E, Vora H, Gong H, Thomas DC: A study of twelve southern California communities with differing levels and types of air pollution: II. Effects on pulmonary function. Am J Respir Crit Care Med 1999, I 59:768-775.

31. Roemer W, Hoek G, Brunekreef B: Pollution effects on asthmatic children in Europe, the PEACE study. Clinical and Experimental Allergy 2000, 30:1067-1075.

32. Ward D, Ayres J: Particulate air pollution and panel studies in children: a systematically review. Occup Environ Med 2004, 6l:el3.

33. Lagorio S, Forastiere F, Pistelli R, lavarone I, Michelozzi P, Fano V Marconi A, Ziemacki G, Ostro BD: Air pollution and lung function among susceptible adult subjects: a panel study. Environ Health 2006, 5: II.

34. Mar T, Koenig J, Jansen K, Sullivan J, Kaufman J, Trenga CA, Siahpush $\mathrm{SH}$, Liu LS, Neas L: Fine particulate air pollution and cardiorespiratory effects in the elderly. Epidemiology 2005, 1 6:68I-687.

35. Pope CA 3rd, Hansen ML, Long RW, Nielsen KR, Eatough NL, Wilson WE, Eatough DJ: Ambient particulate air pollution, heart rate variability, and blood markers of inflammation in a panel of elderly subjects. Environ Health Perspect 2004, I I 2:339-345.

36. Trenga CA, Sullivan JH, Schilderout JS, Shepherd KP, Shapiro GG, Liu LJS, Kaufman JD, Koenig JQ: Effect of particulate air pollution on lung function in a Seattle panel study. Chest 2006, 129:1614-1622.

37. Zanobetti A, Canner M, Stone P, Schwartz J, Sher D, Eagan-Bengston E, Gates KA, Hartley LH, Suh H, Gold DR: Ambient pollution and blood pressure in cardiac rehabilitation patients. Circulation 2004, I 1 0:2184-2189.

38. Abbey D, Nishino N, McDonnell WF, Burchetter PJ, Knutsen SF, Beeson WL, Yang JX: Long-term inhalable particles and other air pollutants related to mortality in nonsmokers. Am J Respir Crit Care Med 1999, I59:373-382.

39. Dockery DW, Pope C III, Spengler JD, Ware JH, Fay ME, Ferris BG, Speizer FE: An association between air pollution and mortality in six U.S. cities. N Engl ] Med I993, 329:।753-I759.

40. Enstrom J: Fine particulate air pollution and total mortality among elderly Californians, 1973-2002. Inhal Toxicol 2005, I 7:803-816.
4I. Lipfert F, Perry H, Miler J, Baty JD, Wyzga RE, Carmody SE: Air pollution, blood pressure, and their long-term associations with mortality. Inhal Toxicol 2003, I5:493-5 I2.

42. McConnell R, Berhane K, Gilliland F, London SJ, Islam T, Gauderman WJ, Avol E, Margolis HG, Peters JM: Asthma in exercising children exposed to ozone: a cohort study. Lancet 2002 , 359:386-39I.

43. Pope C III, Thun M, Namboodiri M, Dockery DW, Evans JS, Speizer $\mathrm{FE}$, Heath CW: Particulate air pollution as a predictor of mortality in a prospective study of U.S. adults. Am J Respir Crit Care Med 1995, I 5 I (3 Pt I):669-674

44. Pope C III, Burnett R, Thun M, Calle EE, Krewski D, Ito K, Thurston GD: Lung cancer, cardiopulmonary mortality, and long-term exposure to fine particulate air pollution. JAMA 2002 , 287: I|32-I|4|.

45. Clancy L, Goodman P, Sinclair H, Dockery DW: Effect of air pollution control on death in Dublin, Ireland: an intervention study. Lancet 2002, 360: $1210-12 \mid 4$

46. Filleul L, Rondeau V, Vandentorren S, Moual NL, Cantagrel A, AnnesiMaesano I, Charpin D, Declercq C, Neukirch F, Paris C, Vervloet D, Brochard P, Tessier JF, Kauffmann F, Baldiet I: Twenty five year mortality and air pollution: results from French PAARC survey. Occup Environ Med 2005, 62:453-460.

47. Frostad A, Søyseth V, Andersen A, Gulsvik A: Respiratory symptoms as predictors of all-cause mortality in an urban community: a 30-year follow-up. J Int Med 2006, 259:520-529.

48. Hoek G, Brunekreef B, Goldbohm S, Fischer P, Brandt PA: Association between mortality and indicators of traffic-related air pollution in the Netherlands. Lancet 2002, 360:1203-1209.

49. Jalaludin B, O'Toole B, Leeder S: Acute effects of urban ambient air pollution on respiratory symptoms, asthma medication use, and doctor visits for asthma in a cohort of Australia children. Environ Res 2004, 95:32-42.

50. Šrám RJ, Binková B, Dejmek J, Bobak M: Ambient air pollution and pregnancy outcomes: a review of the literature. Environ Health Perspect 2005, I I 3(4):375-382.

5I. Selevan SG, Kimmel CA, Mendola P: Identifying Critical Windows of Exposure for Children's Health. Environ Health Perspect 2000, I 08(suppl):45 I-455.

52. Maisonet M, Bush T], Correa A, Jaakkol J]: Relation between ambient air pollution and low birth weight in the northeastern United States. Environ Health Perspect 200I, I09(suppl 3):35I-356.

53. Liu S, Krewski D, Shi Y, Chen Y, Burnett RT: Association between gaseous ambient air pollutants and adverse pregnancy outcomes in Vancouver, Canada. Environ Health Perspect 2003, I I I:1773-1778.

54. Woodruff TJ, Parker JD, Schoendorf KC: Fine particulate matter $\left(\mathrm{PM}_{2.5}\right)$ air pollution and selected causes of postneonatal infant mortality in California. Environ Health Perspect 2006, I | 4:786-790.

55. Hansen C, Neller A, Williams G, Simpson R: Maternal exposure to low levels of ambient air pollution and preterm birth in Brisbane, Australia. BJOG 2006, I I 3:935-94I

56. Slama R, Morgenstern V, Cyrys J, Zutavern A, Herbarth O, Wichmann HE, Heinrich J, the LISA Study Group: Traffic-related atmospheric pollutants levels during pregnancy and offspring's term birth weight: a study relying on a land-use regression exposure model. Environ Health Perspect 2007, I I 5: | 283- I 292.

57. Bell ML, Ebisu K, Belanger K: Ambient air pollution and low birth weight in Connecticut and Massachusetts. Environ Health Perspect 2007, I 15:1 I 18-1 125

58. Hansen CA, Barnett AG, Pritchard G: The effect of ambient air pollution during early pregnancy on fetal ultrasonic measurements during mid-pregnancy. Environ Health Perspect 2008 , I | 6:362-369.

59. Ritz B, Wilhelm M, Hoggatt KJ, Ghosh JKC: Ambient air pollution and preterm birth in the environment and pregnancy outcomes study at the University of California, Los Angles. Am J Epidemiol 2007, 166: 1045-1052.

60. Parker JD, Woodruff TJ, Basu R, Schoendorf KC: Air pollution and birth weight among term infants in California. Pediatrics 2005 , I | 5: $121-128$.

61. Hedley A, Wong C, Thach T, Ma S, Lam TH, Anderson HR: Cardiovascular and all-cause mortality after restrictions on sulphur 
content of fuel in Hong Kong: an intervention study. Lancet 2002, 360:1646-1652.

62. Cakmak S, Burnett R, Krewski D: Methods for detecting and estimating population threshold concentrations for air pollution-related mortality with exposure measurement error. Risk Anal 1999, 19:487-496.

63. Daniels M, Dominci F, Samet J, Zeger SL: Estimating particulate matter-mortality dose-response curves and threshold levels: an analysis of daily time-series for the $\mathbf{2 0}$ largest US cities. Am J Epidemiol 2000, I 52:397-406.

64. Clyde M: Model uncertainty and health effect studies for particulate matter. Environmetrics 2000, I I:745-763.

65. SAS Institute Inc: SAS/STATE 9.I User's Guide. Cary, NC: SAS Institute Inc; 2004:32 I 3-3332.

66. Sarnat JA, Wilson WE, Strand M, Brook J, Wyzga R, Lumley T: Panel discussion review: session one - exposure assessment and related errors in air pollution epidemiologic studies. J Expo $\mathrm{Sc}$ Environ Epidemiol 2007, 17:s75-s82.

67. Jerret M, Arain A, Kanaroglou P, Beckerman B, Potoglou D, Sahsuvaroglu T, Morrison J, Giovis C: A review and evaluation of intraurban air pollution exposure models. J Expo Anal Environ Epidemiol 2005, 15:185-204

68. Dominici F, Sheppard L, Clyde M: Health effects of air pollution a statistical review. International Statistic Review 2003, 71:243-276.

69. Maclure M: The case-crossover design: a method for study transient effects on the risk of acute events. Am J Epidemiol 1991, I33:| 144-153.

70. Hastie TJ, Tibshirani RJ: Generalized Additive Models. New York: Chapman \& Hall; 1990

71. Ritz B, Yu F: The Effect of Ambient Carbon Monoxide on Low Birth Weight among Children Born in Southern California between 1989 and 1993. Environ Health Perspect 1999, 107:17-25.

72. Wilhelm M, Ritz B: Local variations in $\mathrm{CO}$ and particulate air pollution and adverse birth outcomes in Los Angeles County, California, USA. Environ Health Perspect 2005, I 13:1212-1221.

73. Ritz B, Wilhelm M: Ambient air pollution and adverse birth outcomes: methodological issues in an emerging field. Basic Clin Pharmacol Toxicol 2008, 102:182-190.

74. Rotheman KJ, Greenland S: Modern Epidemiology 2nd edition. New York: Lippincott Williams \& Wilkins; 1998.

75. Katsouyanni K, Pantazopoulou A, Touloumi G: Evidence for interaction between air pollution and high temperature in the causation of excess mortality. Arch Environ Health 1993, 48:235-242.

76. Ren C, Tong S: Temperature modified he health effects of particulate matter in Brisbane, Australia. Int $j$ Biometeorol 2006, 5 I:87-96.

77. Roberts S: Interactions between particulate air pollution and temperature in air pollution mortality time series studies. Environ Res 2004, 96:328-337.

78. Samet J, Zeger S, Kelshall J, Xu J, Kalkstein L: Does weather confound or modify the association of particulate air pollution with mortality? An analysis of the Philadelphia data, 19731980. Environ Res 1998, 77:9-19.

79. Ren C, Williams GM, Mengersen K, Morawska L, Tong S: Does temperature modify short-term effects of ozone on total mortality in 60 large eastern US communities? - an assessment using NMMAPS data. Environ Int 2008, 34:45I-458.

80. Stafoggia M, Schwartz J, Forastiere F, Perucci CA, the SISTI group: Does temperature modify the association between air pollution and mortality? A multicity case-crossover analysis in Italy. Am J Epidemiol 2008, 167: 1476-I485.

8I. Ren C, Williams G, Tong S: Does Particulate Matter Modify the Association between Temperature and Cardiorespiratory Diseases? Environ Health Perspect 2006, I I 4:1690-1696.

82. Ren C, Williams GM, Morawska L, Mengersen K, Tong S: Ozone modifies associations between temperature and cardiovascular mortality: analysis of the NMMAPS data. Occup Environ Med 2008, 65:255-260.

83. Peters A, Skorkovsky J, Kotesovec F, Brynda J, Spix C, Wichmann HE, Joachim Heinrich J: Associations between mortality and air pollution in central Europe. Environ Health Perspect 2000, 108:283-287.
84. Schwartz J: Assessing confounding, effect modification, and threshold in the association between ambient particles and daily deaths. Environ Health Perspect 2000, 108:563-568.

85. Hales S, Salmond C, Town Gl, Kjellstrom T, Woodward A: Daily mortality in relation to weather and air pollution in Christchurch, New Zealand. Aust ZN Public Health 2000, 24:89-9l.

86. Wong TW, Tam WS, Yu TS, Wong AHS: Associations between daily mortalities from respiratory and cardiovascular diseases and air pollution in Hong Kong, China. Occup Environ Med 2002, 59:30-35.

87. $\mathrm{Kim} \mathrm{H}, \mathrm{Kim} Y$, Hong YC: The lag-effect pattern in the relationship of particulate air pollution to daily mortality in Seoul, Korea. Int J Biometeorol 2003, 48:25-30.

88. Kan H, Chen B: Air pollution and daily mortality in Shanghai: a time-series study. Arch Environ Health 2003, 58:360-367.

89. Petroeschevsky A, Simpson RW, Thalib L, Rutherford S: Associations between outdoor air pollution and hospital admissions in Brisbane, Australia. Arch Environ Health 200I, 56:37-52.

90. Braga AL, Saldiva PH, Pereira LA, Menezes JC, Conceicai JM, Lin CA Zanobetti A, Schwartz J, Dockery DW: Health effects of air pollution exposure on children and adolescents in Sao Paulo, Brazil. Pediatr Pulmonol 2001, 31:106-113.
Publish with Bio Med Central and every scientist can read your work free of charge

"BioMed Central will be the most significant development for disseminating the results of biomedical research in our lifetime. "

Sir Paul Nurse, Cancer Research UK

Your research papers will be:

- available free of charge to the entire biomedical community

- peer reviewed and published immediately upon acceptance

- cited in PubMed and archived on PubMed Central

- yours - you keep the copyright 